\title{
Serum Exosomal miRNA-1915-3p Is Correlated With Disease Activity of Korean Rheumatoid Arthritis
}

\author{
MI-KYOUNG LIM ${ }^{1}$, JIHYUNG YOO ${ }^{1}$, DONG-HYUK SHEEN ${ }^{1}$,

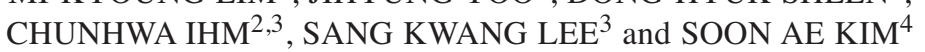 \\ ${ }^{1}$ Department of Internal Medicine, School of Medicine, Eulji University, Daejeon, Republic of Korea; \\ ${ }^{2}$ Department of Laboratory Medicine, School of Medicine, Eulji University, Daejeon, Republic of Korea; \\ ${ }^{3}$ Eulji Medical Bio Research Center, Eulji University, Daejeon, Republic of Korea; \\ ${ }^{4}$ Department of Pharmacology, School of Medicine, Eulji University, Daejeon, Republic of Korea
}

\begin{abstract}
Background/Aim: It has been found that microRNAs (miRNA) affect rheumatoid arthritis (RA) pathophysiology. This study aimed to identify novel serum exosomal miRNAs related to $R A$ disease activity in patients with an inadequate treatment response. Patients and Methods: The sample population comprised clinical remission (CR) and non-clinical remission (non-CR) groups of RA patients. To identify potent miRNA markers for RA disease activity, miRNA array and qPCR were performed after patient serum exosomes preparation. Results: Has-miR1915-3p and has-miR-6511b-5p were significantly higher in the serum exosomes of the CR group. The level of serum $C$ reactive protein $(C R P)$ was negatively correlated with hasmiR-1915-3p level in serum exosomes. Conclusion: HasmiR-1915-3p may be a potential marker for Korean RA disease activity.
\end{abstract}

Exosomes are membrane-bound vesicles $40-100 \mathrm{~nm}$ in diameter that play an important role during information exchange between cells. Exosomes deliver their contents into the cytosol of neighboring cells through secretion and multivesicular body fusion with the plasma membrane of these cells (1). These contents include microRNA (miRNA) molecules, also known as non-coding RNA (ncRNA) molecules, which are associated with the pathogenesis of various diseases (2). Although the specific function of ncRNAs is largely unknown, exosomal RNA is known to

This article is freely accessible online.

Correspondence to: Soon Ae Kim, Department of Pharmacology, School of Medicine, Eulji University, Daejeon 34824, Republic of Korea. Tel: +82 422591672, Fax: +82 422591679, e-mail: sakim@eulji.ac.kr

Key Words: Exosomes, microRNA, rheumatoid arthritis, biomarker. play a role in various biological responses in the disease such as Rheumatoid arthritis (3).

Rheumatoid arthritis (RA) is a chronic inflammatory autoimmune disease (4), with $\sim 30-40 \%$ of RA patients showing an adequate treatment response to an optimal dosing regimen of the antimetabolite agent, methotrexate (MTX). Several promising biomarkers for early diagnosis and treatment response have been proposed from a genomics and proteomics perspective (5). Recently, the effect of epigenetics on RA, such as miRNA expression, was shown to contribute to a range of complex mechanisms concerning this disease $(6,7)$. Concerning ncRNAs, Hotair has been reported to be highly expressed in blood mononuclear cells and the serum exosomes of RA patients (3).

In this study, we tried to identify new exosomal miRNAs related to disease activity in RA patients who have shown inadequate response to treatment by using an miRNA array. We also investigated the correlation of miRNA expression levels with various serological parameters of the patients.

\section{Patients and Methods}

In this study, we included 42 female RA patients, who had received MTX for at least six months prior to collection of blood samples at the Eulji University Hospital in the Republic of Korea. All patients met the 2010 American College of Rheumatology/European League against Rheumatism RA classification criteria (8). The disease activity was measured using the 28 -joint disease activity score (DAS) obtained by erythrocyte sedimentation rate (ESR) (DAS28ESR). The RA patients were stratified into two groups according to following criteria: i) clinical remission (CR) group $(n=22)$, with DAS28-ESR $\leq 2.6$, and ii) non-CR group $(n=20)$ with DAS28ESR $>2.6$. According to the principles of the Declaration of Helsinki, an informed consent was obtained from all patients and the institutional review board of the Eulji University Hospital approved this study (Approval Number: 2015-9-02).

The purification and precipitation of serum extracellular vesicles was performed using the ExoQuick solution (System Biosciences Inc., CA, USA) according to the manufacturer's instructions. The Total 


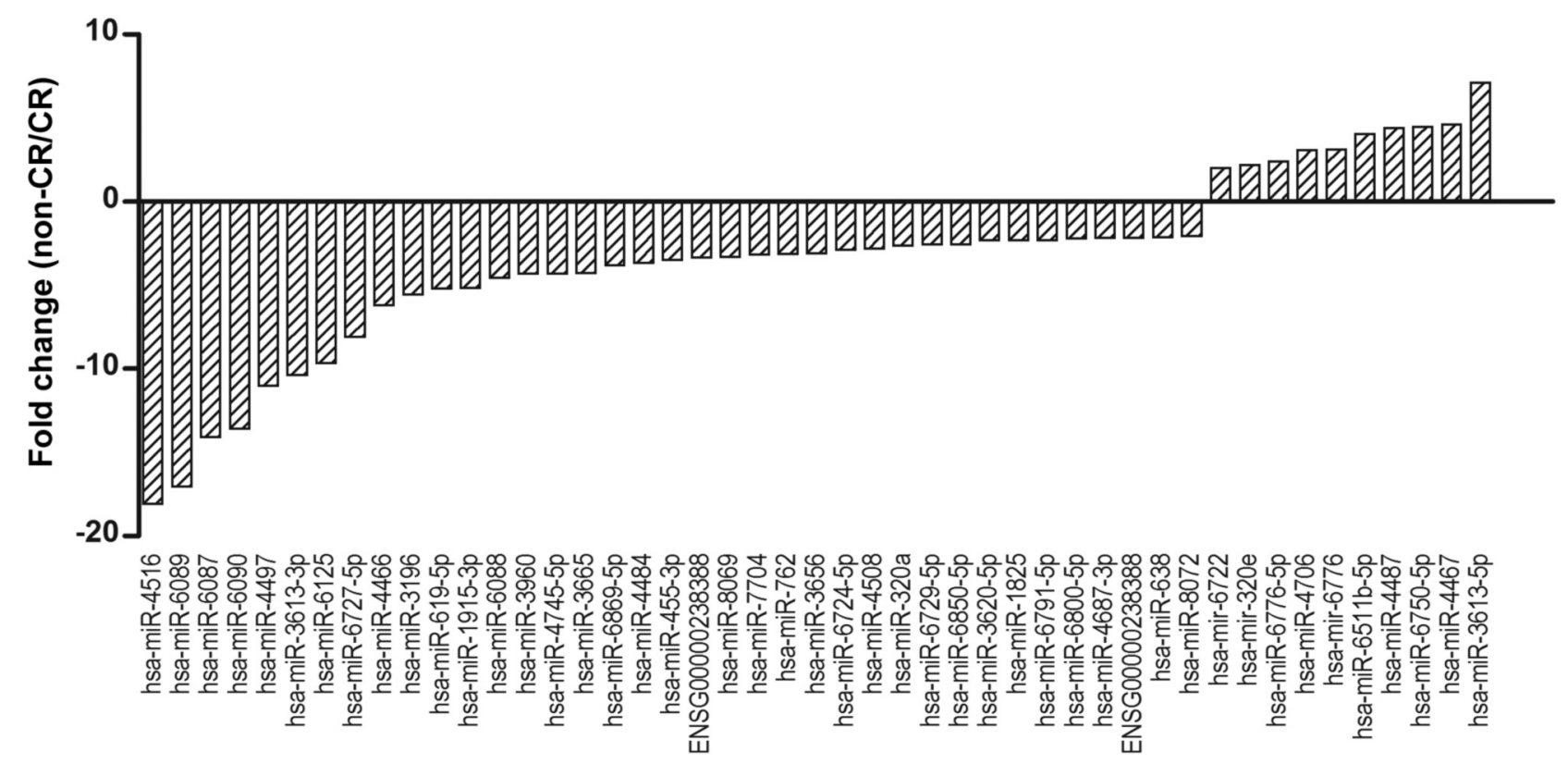

Figure 1. miRNA profiling in serum exosomes using a miRNA array. The graph shows fold-changes between CR and non-CR groups. CR: Clinical remission; miRNA: microRNA; RA: rheumatoid arthritis.

Exosomal RNA and Protein Isolation kit (Invitrogen, Carlsbad, CA, USA) was used for total RNA preparation. After checking the RNA quality by an Agilent 2100 Bioanalyzer (Agilent Technologies, Palo Alto, CA, USA), we used 1ug total RNA by pooling with the same amount (54ng) of total RNA from each sample in the same group. To find new miRNA markers, we used the Affymetrix Genechip miRNA 4.0 Array (Affymetrix; Thermo Fisher Scientific, Inc., Waltham, MA, USA), in accordance with the manufacturer's protocol.

Quantitative real-time PCR (qRT-PCR) was performed with specific primers for miRNAs to quantify the expression of selected miRNAs of each sample in one particular group (miScript System; Qiagen, Inc., Valencia, CA, USA). Five miRNAs: i) hsa-miR-4516 (assay-ID: MS00037555), ii) hsa-miR-3613-3p (assay-ID: MS00031787), iii) hsa-miR-1915-3p (assay-ID: MS00044604), iv) hsa-miR-3665 (assay-ID: MS00043736), and v) hsa-miR-6511b-5p (assay-ID: MS00045661) were selected. SNORD96A_11 was used as the endogenous control (assay-ID: MS00033733) for normalization. Threshold cycle $(\mathrm{Ct})$ values were used to calculate the relative miRNA expression using the $\Delta \mathrm{Ct}$ method. Each reaction was run in duplicate and each experiment was performed at least twice. A comparison between groups was performed using the Student's $t$-test or the Mann-Whitney $U$-test, and Spearman's correlation coefficients (@) were calculated. All statistical analyses were performed using the SPSS program for Windows, Standard Version (version 19.0, SPSS Inc., Chicago, IL, USA) and $p$ Values $<0.05$ were considered significant.

\section{Results}

The clinical and serological features of the $22 \mathrm{CR}$ and 20 non-CR group patients are shown in Table I. There was no significant difference in disease duration, rheumatoid factor
Table I. Patient clinical characteristics.

\begin{tabular}{|c|c|c|c|}
\hline Parameters & CR group & Non-CR group & $p$-Value \\
\hline Age (mean \pm SD, years) & $53.3 \pm 9.26$ & $52.6 \pm 9.48$ & 0.34 \\
\hline Female, $\mathrm{n}$ ( $\%$ of total $)$ & $22(100)$ & $20(100)$ & N/A \\
\hline $\begin{array}{l}\text { Disease duration, } \\
\text { median (IQR), years }\end{array}$ & $6.65(4-12.5)$ & $12.85(2.8-15)$ & 0.43 \\
\hline $\begin{array}{l}\text { RF-positive, } \mathrm{n} \\
\text { (\% of total) }\end{array}$ & $17(77.2 \%)$ & $14(70.0 \%)$ & 0.73 \\
\hline $\begin{array}{l}\text { Anti CCP antibody- } \\
\text { positive, n ( } \% \text { of total) }\end{array}$ & $13(59.1 \%)$ & $19(95.0 \%)$ & $0.008^{*}$ \\
\hline $\begin{array}{l}\text { CRP, median (IQR), } \\
\mathrm{mg} / \mathrm{dl}\end{array}$ & $0.09(0.04-0.11)$ & $1.27(0.37-2.58)$ & $<0.001 *$ \\
\hline $\begin{array}{l}\text { MTX dosage, median } \\
(\mathrm{IQR}), \mathrm{mg} / \text { week }\end{array}$ & $15(12.5-15)$ & $15(15-15)$ & 0.68 \\
\hline $\begin{array}{l}\text { Use of corticosteroid, } \\
\mathrm{n}(\% \text { of total })\end{array}$ & $4(18.2 \%)$ & $19(95.0 \%)$ & $<0.001^{*}$ \\
\hline
\end{tabular}

${ }^{*} p<0.05$. CCP: Cyclic citrullinated peptide; CR: clinical remission; CRP: c-reactive protein; IQR: interquartile range; MTX: methotrexate; RF: rheumatoid factor; SD: standard deviation.

(RF), or dosage of MTX among the patients in both groups.

After the miRNA array data were processed for relative quantification of miRNA expression in exosomes for the CR and non-CR groups, we identified 47 miRNAs with a relative 2 -fold change (non-CR/CR) (Figure 1).

We performed qPCR experiments to validate the miRNA markers and found that the CR group showed higher levels of hsa-miR-1915-3p, hsa-miR-6511b-5p, hsa-miR-3665, and hsa- 

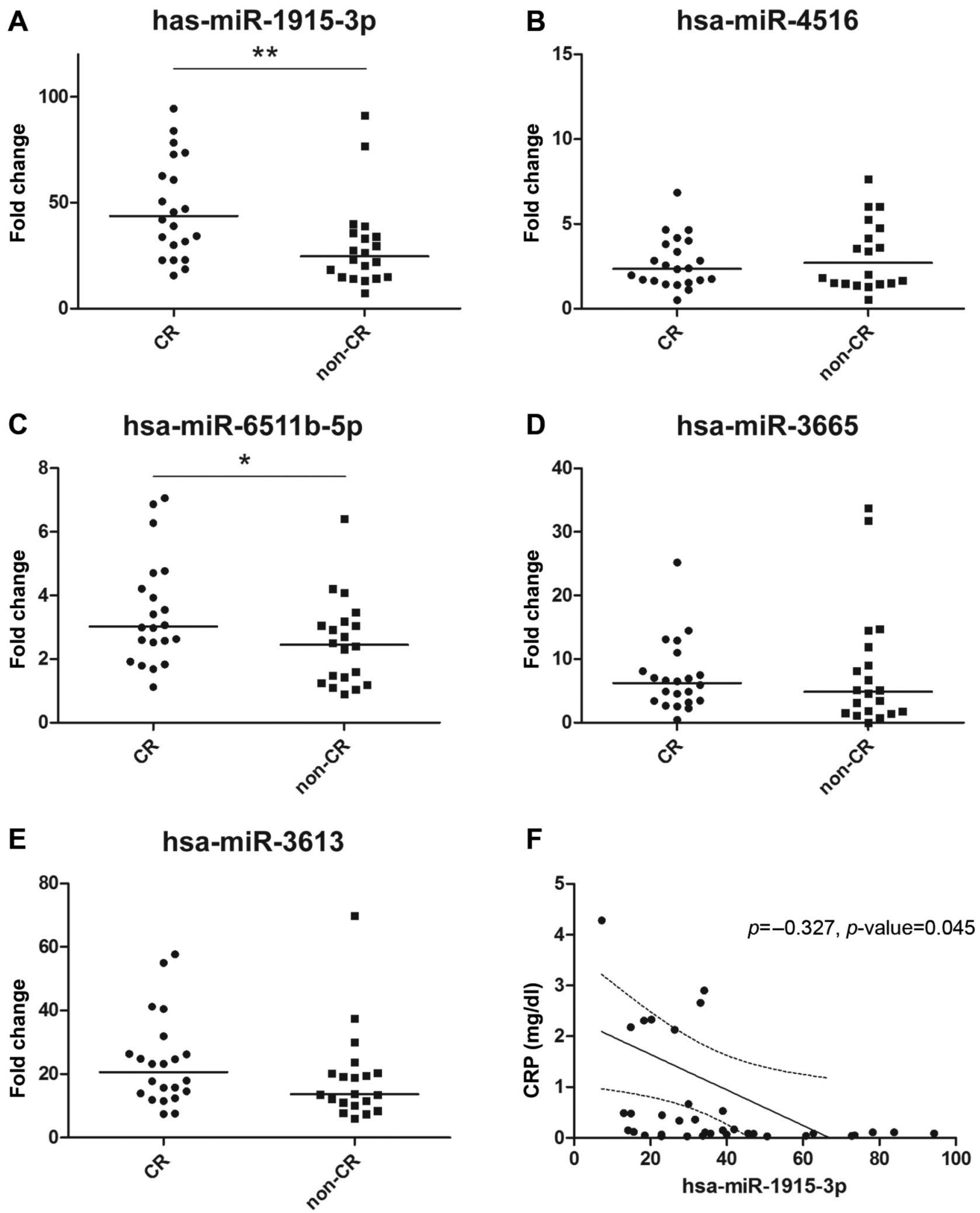

Figure 2. Relative fold change of miRNA levels in serum exosomes compared between CR and non-CR groups of RA patients. A) hsa-miR-1915-3p, B) hsa-miR-4516, C) hsa-miR-6511b-5p, D) hsa-miR-3665, E) hsa-miR-3613, and F) Correlation between hsa-miR-1915-3p and c-reactive protein $(C R P) .{ }^{*} p<0.01, * p<0.05$. CR: Clinical remission; miRNA: microRNA; RA: rheumatoid arthritis. 
miR-3613; however, the level of hsa-miR-4516 was higher in the non-CR group. From 5 selected miRNAs, just 2 miRNAs such as hsa-miR-1915-3p and hsa-miR-6511b-5p showed significantly increased expression in the CR group compared to the non-CR group (Figure 2A-E). The level of hsa-miR1915-3p was different between the CR (43.75-fold) and the non-CR group (24.68-fold) ( $p=0.004)$. In addition, the level of hsa-miR-6511b-5p was also higher in the CR group (3.02fold) compared to the non-CR group (2.45-fold) ( $p=0.03)$.

Next, we investigated the correlation of miRNA levels with several clinical variables. The serum C-reactive protein (CRP) level was significantly negatively correlated with the level of hsa-miR-1915-3p in exosomes ( $\mathrm{Q}=-0.327, p=0.045)$ (Figure 2F). There was no correlation between CRP and the levels of other miRNAs in either CR or non-CR groups. In addition, the anti-CCP antibody was significantly correlated with hsa-miR-3613 in the CR group ( $Q=0.465, p=0.039)$; however, it was not correlated with the miRNA levels in the non-CR group.

\section{Discussion}

Recently, study results indicated that biological alterations such as changes in miRNA expression may be involved in the pathogenesis of autoimmune. Several of these miRNAs as well as their associated regulatory cascades are considered important in the autoimmune disorder of RA in different clinical stages of it $(9,10)$. Interestingly, numerous studies have suggested expression changes of miRNAs the in plasma/serum samples of RA patients $(6,11,12)$, however there is lack of data with regards to the link between the disease activity of RA and these miRNA markers.

In this study, we evaluated miRNA levels in serum exosomes of RA patients and suggested that one of the miRNAs, hsa-miR1915-3p, correlates with the disease activity of RA.

Though its exact function remains unknown, hsa-miR1915-3p is considered as one of the dysregulated miRNAs in various types of cancers (13), while it has been reported that oxidative stress up-regulates hsa-miR-1915-3p (14). It is suggested that activated neutrophils are included in the synovial fluid of the inflamed rheumatoid joint and Neutrophils in the synivial fluid of RA patients show enhanced $\mathrm{O}_{2}^{-}$production by inflammatory cytokines exposure. Furthermore, Ischemia and reperfusion during movements are considered to contribution of the production of reactive oxygen species (ROS) in the synovial fluid of the inflamed rheumatoid joint (15). Another study has shown that RA patients have significantly higher levels of prooxidants (superoxide anion radical, hydrogen peroxide, and thiobarbituric acid reactive substances) compared to healthy controls, and significant differences were observed in the serum levels of nitric oxide in patients with high disease activity (16). Taken together, hsa-miR-1915-3p is negatively associated with the disease activity of RA as an oxidative stress-responsive miRNA.

In conclusion, we suggested that exosomal hsa-miR-1915$3 p$ may be a bio-marker that can assess the disease activity of RA patients. Some limitations in our study include the sample size, the lack of healthy controls and the fact that this was a simple cross-sectional study design. Further investigation about hsa-miR-1915-3p may be useful for the development of novel tools concerning the disease activity and prognosis in RA as well as other autoimmune diseases. In addition, further research with a large number of samples and additional miRNAs in known pathways is also warranted.

\section{Conflicts of Interest}

The Authors declare that they have no conflicts of interest in regard to this study.

\section{Authors' Contributions}

ML: Data collection, analysis, and interpretation of results and writing/editing of the original article; JY: data analysis, statistical analyses, construction of a figure and writing of the original article; DS: data collection, editing of the original article and patient management; $\mathrm{CI}$; data collection, editing and writing of the original article; SKL; data collection, analysis, and interpretation of results and writing/editing of the original article; SAK: supervision of the project, study design, data analysis, construction of a figure and writing/editing of the original article. All the Authors read and approved the final article.

\section{Acknowledgements}

The Authors would like to thank Ms. Tae Yeon Kim for help in the exosome preparation experiment. This work was supported by the National Research Foundation of Korea (NRF) grant funded by the Korean government (MSIP) (2016M3A9B694241) and this research was also supported by EMBRI Grants 2014 (2014 EMBRISN0003) from the Eulji University.

\section{References}

1 Mulcahy LA, Pink RC and Carter DRF: Routes and mechanisms of extracellular vesicle uptake. J Extracell Vesicles 4: 3, 2014. PMID: 25143819. DOI: 10.3402/jev.v3.24641

2 Kim J, Kim TY, Lee MS, Mun JY, Ihm C and Kim SA: Exosome cargo reflects TGF- $\beta 1$-mediated epithelial-to-mesenchymal transition (EMT) status in A549 human lung adenocarcinoma cells. Biochem Biophys Res Commun 478(2): 643-648, 2016. PMID: 27492069. DOI: 10.1016/j.bbrc.2016.07.124

3 Song J, Kim D, Han J, Kim Y, Lee M and Jin E-J: PBMC and exosome-derived Hotair is a critical regulator and potent marker for rheumatoid arthritis. Clin Exp Med 15(1): 121-126, 2015. PMID: 24722995. DOI: 10.1007/s10238-013-0271-4

4 Lee DM and Weinblatt ME: Rheumatoid arthritis. Lancet 358(9285): 903-911, 2001. PMID: 11567728. DOI: 10.1016/ S0140-6736(01)06075-5 
5 Halilova KI, Brown EE, Morgan SL, Bridges SL, Hwang MH, Arnett DK and Danila MI: Markers of treatment response to methotrexate in rheumatoid arthritis: Where do we stand? Int J Rheumatol 2012: 978396, 2012. PMID: 22844292. DOI: $10.1155 / 2012 / 978396$

6 Castro-Villegas C, Pérez-Sánchez C, Escudero A, Filipescu I, Verdu M, Ruiz-Limón P, Aguirre MA, Jiménez-Gomez Y, Font P, Rodriguez-Ariza A, Peinado JR, Collantes-Estévez E, González-Conejero R, Martinez C, Barbarroja N and LópezPedrera C: Circulating miRNAs as potential biomarkers of therapy effectiveness in rheumatoid arthritis patients treated with anti-TNF $\alpha$. Arthritis Res Ther 17(1): 49, 2015. PMID: 25860297. DOI: 10.1186/s13075-015-0555-z

7 Singh RP, Massachi I, Manickavel S, Singh S, Rao NP, Hasan S, Mc Curdy DK, Sharma S, Wong D, Hahn BH and Rehimi H: The role of miRNA in inflammation and autoimmunity. Autoimmun Rev 12(12): 1160-1165, 2013. PMID: 23860189. DOI: 10.1016/j.autrev.2013.07.003

8 Aletaha D, Neogi T, Silman AJ, Funovits J, Felson DT, Bingham CO 3rd, Birnbaum NS, Burmester GR, Bykerk VP, Cohen MD, Combe B, Costenbader KH, Dougados M, Emery P, Ferraccioli G, Hazes JM, Hobbs K, Huizinga TW, Kavanaugh A, Kay J, Kvien TK, Laing T, Mease P, Ménard HA, Moreland LW, Naden RL, Pincus T, Smolen JS, Stanislawska-Biernat E, Symmons D, Tak PP, Upchurch KS, Vencovsky J, Wolfe F and Hawker G: 2010 rheumatoid arthritis classification criteria: an American College of Rheumatology/European League Against Rheumatism collaborative initiative. Ann Rheum Dis 69(9): 1580-1588, 2010. PMID: 20699241. DOI: 10.1136/ard. 2010.138461

9 Zakeri Z, Salmaninejad A, Hosseini N, Shahbakhsh Y, Fadaee E, Shahrzad MK and Fadaei S: MicroRNA and exosome: Key players in rheumatoid arthritis. J Cell Biochem 120: 1093010944, 2019. PMID: 30825220. DOI: 10.1002/jcb.28499

10 Furer V, Greenberg JD, Attur M, Abramson SB and Pillinger MH: The role of microRNA in rheumatoid arthritis and other autoimmune diseases. Clin Immunol 136(1): 1-15, 2010. PMID: 20223711. DOI: $10.1016 /$ j.clim.2010.02.005
11 Li J, Wan Y, Guo Q, Zou L, Zhang J, Fang Y, Zhang J, Zhang J, Fu X, Liu H, Lu L and Wu Y: Altered microRNA expression profile with miR-146a upregulation in CD4+ $\mathrm{T}$ cells from patients with rheumatoid arthritis. Arthritis Res Ther 12(3): R81, 2010. PMID: 20459811. DOI: 10.1186/ar3006

12 Murata K, Furu M, Yoshitomi H, Ishikawa M, Shibuya H, Hashimoto M, Imura Y, Fujii T, Ito H, Mimori T and Matsuda $\mathrm{S}$ : Comprehensive microRNA analysis identifies miR-24 and miR-125a-5p as plasma biomarkers for rheumatoid arthritis. PLoS One 8(7): e69118, 2013. PMID: 23874885. DOI: 10.1371/journal.pone.0069118

13 Ceribelli A, Yao B, Dominguez-Gutierrez PR, Nahid MA, Satoh $M$ and Chan EKL: MicroRNAs in systemic rheumatic diseases. Arthritis Res Ther 13(4): 229, 2011. PMID: 21787439. DOI: 10.1186/ar3377

14 Wan Y, Cui R, Gu J, Zhang X, Xiang X, Liu C, Qu K and Lin Ta: Identification of four oxidative stress-responsive microRNAs, miR-34a-5p, miR-1915-3p, miR-638, and miR-150$3 p$, in hepatocellular carcinoma. Oxid Med Cell Longev 2017: 5189138, 2017. PMID: 28811864. DOI: $10.1155 / 2017 / 5189138$

15 Taysi S, Polat F, Gul M, Sari RA and Bakan E: Lipid peroxidation, some extracellular antioxidants, and antioxidant enzymes in serum of patients with rheumatoid arthritis. Rheumatol Int 21(5): 200-204, 2002. PMID: 11958437. DOI: 10.1007/s00296-001-0163-x

16 Veselinovic M, Barudzic N, Vuletic M, Zivkovic V, Tomic-Lucic A, Djuric D and Jakovljevic V: Oxidative stress in rheumatoid arthritis patients: relationship to diseases activity. Mol Cell Biochem 391(1-2): 225-232, 2014. PMID: 24610042. DOI: 10.1007/s11010-014-2006-6
Received May 25, 2020

Revised June 19, 2020

Accepted June 20, 2020 